\title{
Heavy Oil Exploitation: Pushing the Envelope of Enhanced Oil Recovery
}

George Vassilellis

Steam or $\mathrm{CO} 2$ injection methods account for most of the oil recovered worldwide with Enhanced Oil Recovery (EOR) methods. Currently heavy oil production is less than $7 \%$ of the world's oil production; this percentage is not expected to increase dramatically without significant changes in reservoir management. Steam and CO2 have been used successfully since early 1960 s -- steam in viscous heavy oils and $\mathrm{CO} 2$ mostly in pressurized light oil fields but also in some heavy oil fields. What limits a wider application is depth and high pressure for steam and $\mathrm{CO} 2$ availability for the relatively large inventory of light oil fields that exist worldwide. Although there is some overlap in fields that could benefit from either application, there are not many recorded attempts to implement both methods simultaneously. Air injection, although it was tried first as an EOR method, has not been widely implemented as in-situ combustion is difficult to control in shallow reservoirs and especially without water coinjection.

The benefits from a downhole heat generation are known to the industry for decades, but so far there is not any practical application found in today's heavy oil exploitation. A recent conceptual design for Downhole Steam Generation (DHSG) which combines thermal and nitrogen or CO2 EOR, is yet to be tested, but promises to overcome technological barriers and achieve in the field, what has been in theory the obvious benefit; exploiting deeper formations and improve thermal efficiency. In addition to these benefits, today's technology may improve the EOR processes by controlling the ratios of steam, excess $\mathrm{CO} 2$ and excess $\mathrm{O} 2$ (where applicable) it is possible to use in-situ oxidation in a controlled manner and accelerate production of oil. Moreover, the $\mathrm{CO} 2$ that is generated by in situ can be used elsewhere. The paper includes discussion of conceptual reservoir simulation and economic studies that demonstrate the applicability of DHSG in deeper warm-climate conventional heavy oil fields, as well as challenging arctic environments.

Advances in other areas like steam assisted gravity drainage (SAGD), advanced downhome monitoring, Inflow and outflow controlling devices in horizontal completions, high temperature artificial lifting, sand control and polymers/gels may add to these benefits in combination or on their own to achieve the most optimum exploitation plans in heavy oil deposits. 